\title{
Wear Resistance of Hybrid Composite Resin for Crown Material by the Two-body Sliding Test
}

\author{
Kazuhiko SUESE and Takayoshi KAWAZOE ${ }^{1}$ \\ O.D.U. Dental Mechanic College \\ ${ }^{1}$ Dept. of Fixed Prosthodontics, Osaka Dental University \\ 1-4-4 Makinohonmachi, Hirakata city, Osaka, 573-1144, Japan
}

Received March 7, 2002/Accepted June 24, 2002

\begin{abstract}
Comparative studies on two-body sliding wear resistance were performed between a hybrid composite resin and conventional light-curing composite veneering materials. This study investigated the wear resistance of hybrid composite resins compared with three composite resin veneering materials for $12 \% \mathrm{Au}-\mathrm{Ag}-\mathrm{Pd}$ alloy, the wear resistance of four restorative materials opposed to hybrid composite resin, and the influence of surface characteristics on hybrid composite resins. Hybrid composite resin without heat-curing, which was compared with other composite resin materials exhibited inferior wear resistance, but hybrid composite resin mechanically polished after heat-curing exhibited the most superior wear resistance.
\end{abstract}

Key words: Wear resistance, Composite material, Crown

\section{INTRODUCTION}

Esthetic restorative materials are broadly divided into two categories: resinous materials and inorganic materials, with the latter including porcelain and castable glass ceramics. Both types of materials have their own advantages and disadvantages. From a material point of view, it has been noted that resinous materials are softer than natural tooth structure, while inorganic materials are too hard for biocompatibility with natural teeth. Hard resins continue to play an important role for jacket crowns and veneering crowns, but a number of clinical problems associated with their use persist. While most of these problems have been investigated extensively, most progress has been achieved in the area of wear resistance ${ }^{1)}$. Composite resin veneering materials have become more common because of the improved wear resistance of newer materials ${ }^{2-4)}$. Recently, new composite resin materials for posterior full crowns were developed, and the mechanical properties were improved by resin and filler technology, including heat curing in addition to visible-light curing. With its ultrahigh concentration of fine ceramic filler particles, these hybrid composite resins offer exceptional physical properties.

The purpose of this study was to evaluate the wear resistance of a new hybrid composite resin crown material and several conventional veneering light-curing composite materials using the two-body sliding wear testing method. 


\section{MATERIALS AND METHODS}

In this investigation, a new hybrid composite resin ( $\mathrm{HC}$ ) and three kinds of lightcuring composite resin materials (SD, LC, CS) designed for fixed restorative veneering procedures were examined using a two-body sliding wear device (Table 1). Each test specimen had a uniform size $10 \mathrm{~mm} \times 10 \mathrm{~mm}$ in length and width, and $3 \mathrm{~mm}$ in thickness. The surfaces of the specimens were prepared flat in order to press them against a glass plane, and polymerized by light-curing. In addition, the surfaces of the $\mathrm{HC}$ were ground flat using a conventional, mechanical polishing technique after heat-curing. As opposing specimens, balls of $6 \mathrm{~mm}$ in diameter were fabricated using $12 \% \mathrm{Au}-\mathrm{Ag}-\mathrm{Pd}$ alloy, mechanically polishing $\mathrm{HC}$ and castable glass ceramics, and enamels of an extracted mandibular premolar were prepared. The wear resistance of pairs of materials are given in Table 2. The opposing specimens were centrally positioned on each sliding test specimen. They were vertically loaded and tested at $1.0 \mathrm{kgf}$. The test was conducted at a rate of 120 cycles per minute and a stroke of $5 \mathrm{~mm}$ each. The cycling procedure was carried out 10,000, 50,000, 100,000 and 200,000 cycles under running water (Fig. 1 and Fig. 2). The wear track was defined as the distance from the surface of the specimens to the base of the deepest and widest defect generated by a wear testing device after 200,000 cycles. The surfaces of the worn specimens were observed with a scanning electron microscope. The area of contact of the worn alloy ball, enamel, $\mathrm{HC}$ and castable glass ceramic (CPCC) after each cycle was also measured by the silicone replica method. The ratio

Table 1 Materials investigated in this study

\begin{tabular}{lllc}
\hline \multicolumn{1}{c}{ Material type } & \multicolumn{1}{c}{ Products } & \multicolumn{1}{c}{ Manufacturer } & code \\
\hline Hybrid composite resin & Estenia & Kuraray, Osaka, Japan & HC \\
Veneering light-curing composite resin & Solidex & Shofu, Kyoto, Japan & SD \\
& Thermoresin LC & GC, Tokyo, Japan & LC \\
& Cesead II & Kuraray, Osaka, Japan & CS \\
$12 \%$ Au-Ag-Pd alloy & Castwell M.C. & GC, Tokyo, Japan & Pd \\
Castable glass ceramic & Cry-cera & Kyutai dentceram & CPCC \\
Enamel & Extracted mandibular premolar & Enamel \\
\hline
\end{tabular}

Table 2 Matericl couples of wear resistance for each experiment

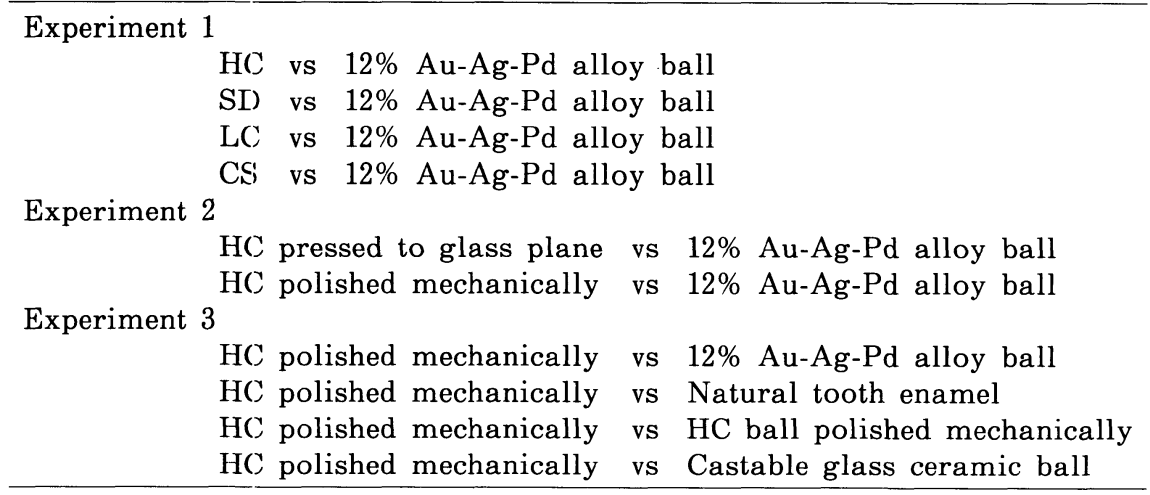




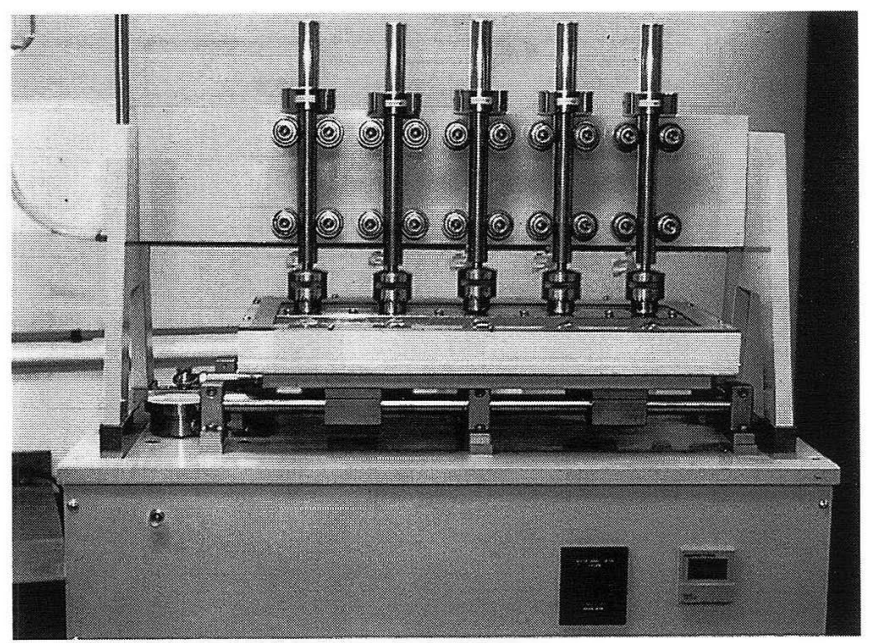

Fig. 1 Two-body sliding wear testing machine.

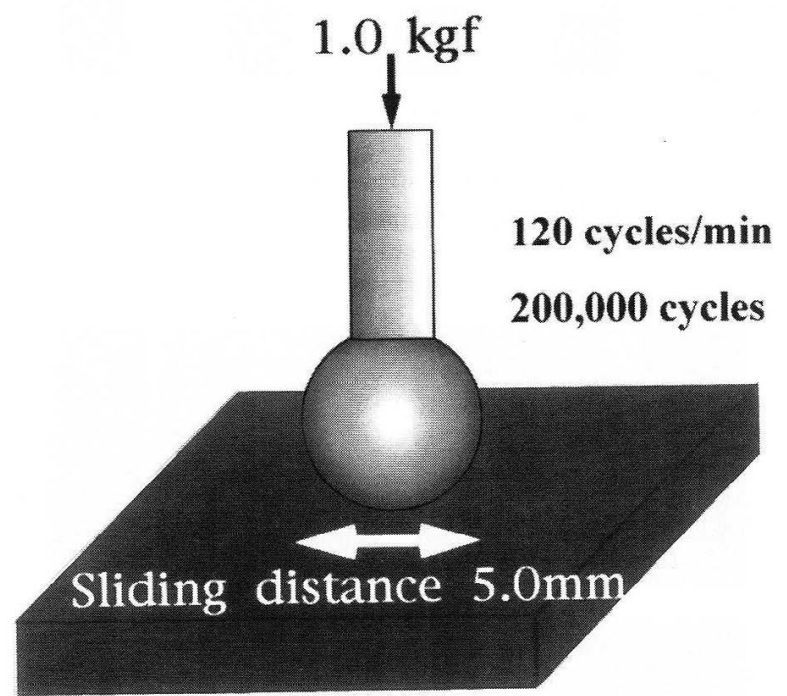

\section{$10 \times 10 \times 3 \mathrm{~mm}$}

Fig. 2 Schematic of the sliding wear apparatus.

of the worn area after each sliding number of times for the original contact area of each material ball was calculated as the changing ratio. The surface hardness values (Vickers hardness number) of the hybrid composite resin, three composite resins, $12 \% \mathrm{Au}-\mathrm{Ag}-\mathrm{Pd}$ alloy and castable glass ceramics were measured prior to the sliding wear test.

The results were statistically analysed by means of one-way analysis of variance (ANOVA) followed by Fisher's t test. 

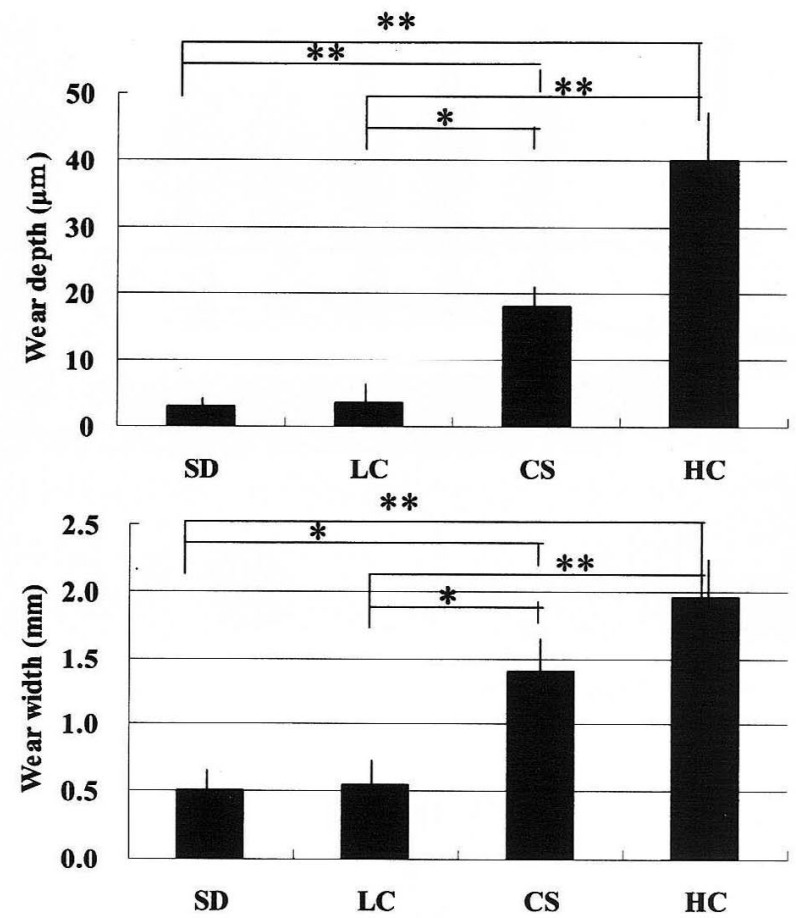

Fig. 3 Maximal depth and width of the wear tracks of each composite resin.

(Significant difference ${ }^{*}: \mathrm{p}<0.05,{ }^{* *}: \mathrm{p}<0.01$ )
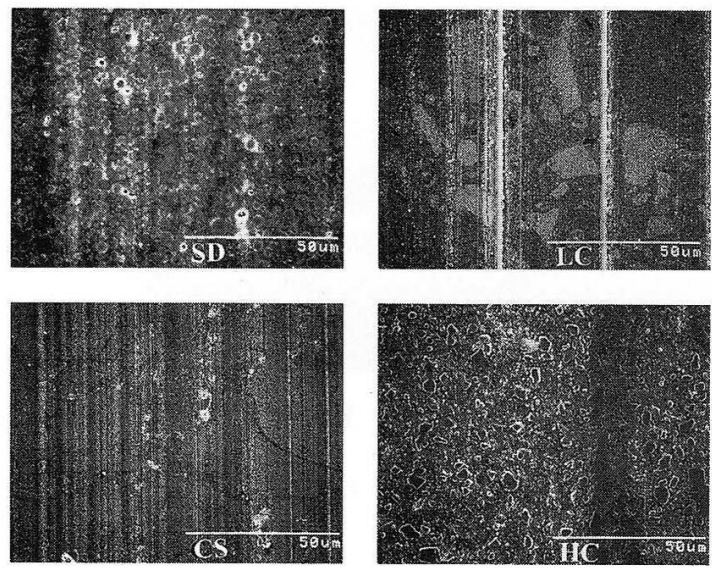

Fig. 4 SEMs of the wear tracks of each composite resin opposed by $12 \% \mathrm{Au}-\mathrm{Ag}-\mathrm{Pd}$ alloy.

\section{RESULTS}

Figure 3 shows the maximal depth and width of wear of $\mathrm{HC}$ and three veneering 

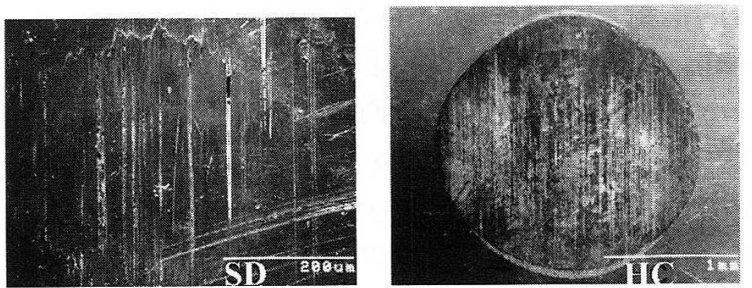

Fig. 5 SEMs of $12 \%$ Au-Ag-Pd alloy balls worn by $\mathrm{HC}$ and SD.
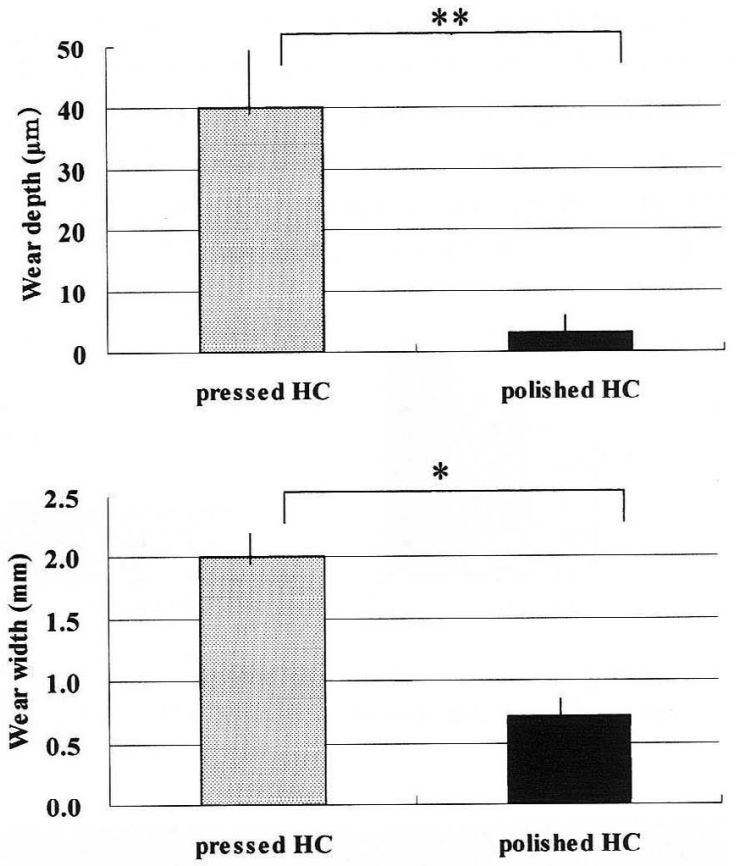

Fig. 6 Maximal depth and width of the wear tracks of $\mathrm{HC}$ with two differently prepared surfaces.

pressed HC: press to a flat glass plane, and polymerized by light-curing polished HC: mechanical polishing after heat-curing pressed $\mathrm{HC}$

(Significant difference ${ }^{*}: \mathrm{p}<0.05,{ }^{* *}: \mathrm{p}<0.01$ )

composite resins (SD, LC and CS) when opposed by $12 \%$ Au-Ag-Pd alloy balls after 200,000 cycles. The depth values of HC averaged $40.8 \mu \mathrm{m}$, whereas other composite resins were $2.7 \mu \mathrm{m}$ to $18.3 \mu \mathrm{m}$. One-way ANOVA and the $\mathrm{t}$ test showed that $\mathrm{HC}$ possessed significantly larger depth values than SD, LC or CS $(\mathrm{P}<0.05)$. The wear width values of $\mathrm{HC}$ averaged $1,980 \mu \mathrm{m}$, whereas other composite resins were $460 \mu \mathrm{m}$ to $1,380 \mu \mathrm{m}$. One-way ANOVA and the $\mathrm{t}$ test showed that $\mathrm{HC}$ possessed significantly 
larger width values than SD, LC or CS $(\mathrm{P}<0.001)$. Scanning electron micrographs of various composite resin veneering materials and each worn ball observed on completion of the wear testing are presented in Figs. 4 and 5. The SEMs of wear tracks of SD (top-left), LC (top-right), CS (bottom-left) and HC (bottom-right) opposed by $12 \%$ Au-Ag-Pd alloy balls after 200,000 cycles are shown in Fig. 4. The SEM of HC material showed the submicron-sized filler particles protruding from the surface. The SEMs of the alloy ball worn by $\mathrm{HC}$ and SD are shown in Fig. 5. In the case of HC material, the worn alloy ball surface showed well-defined margins and wear tracks generated by hard micro-filler, whereas in the SD material, there was an irregular margin and no wear tracks. Figure 6 shows the maximum depth and width of wear of $\mathrm{HC}$ with two different surfaces when opposed by $12 \% \mathrm{Au}-\mathrm{Ag}$-Pd alloy balls after 200,000 cycles. HC ground flat using conventional mechanically polishing after heat-curing was more wear resistant than HC prepared flat in order to press against a glass plane with light-curing. A significant difference $(\mathrm{P}<0.01)$ was noted between the two differently prepared surfaces (Fig.6). The changing ratio of worn $12 \% \mathrm{Au}-\mathrm{Ag}-\mathrm{Pd}$ alloy balls of mechanically polished HC specimens was half that of

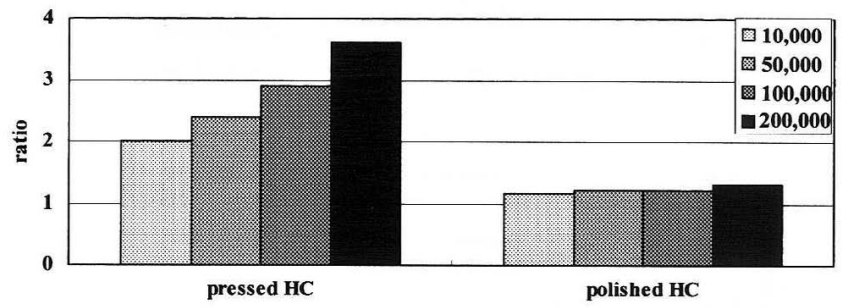

Fig. 7 Changing ratio of worn areas of alloy balls against two differently prepared HC surfaces.

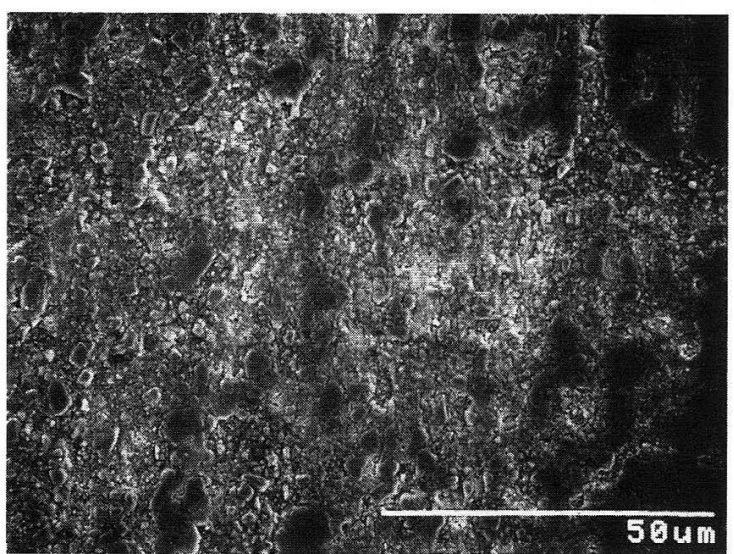

Fig. 8 SEM of the wear tracks of mechanically polished $\mathrm{HC}$ opposed by $12 \% \mathrm{Au}-\mathrm{Ag}-\mathrm{Pd}$ alloy. 


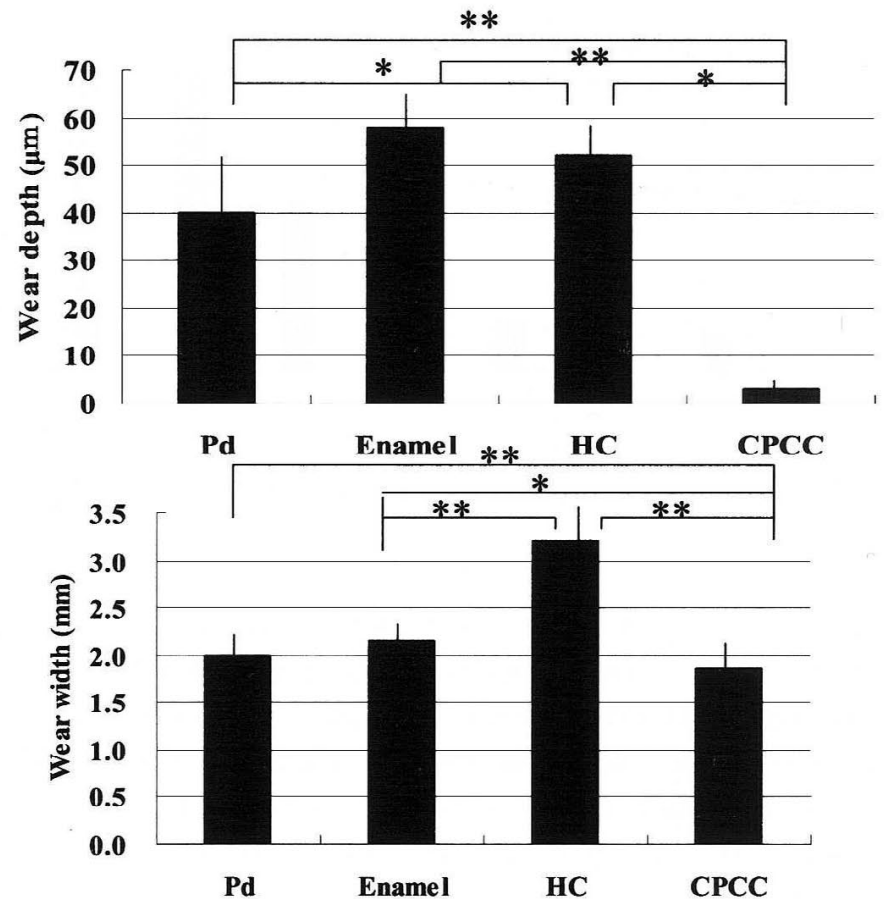

Fig. 9 Maximal depth and width of the wear tracks of HC opposed by alloy, enamel, $\mathrm{HC}$ and castable glass ceramic.

(Significant differences ${ }^{*}: \mathrm{p}<0.05,{ }^{* *}: \mathrm{p}<0.01$ )

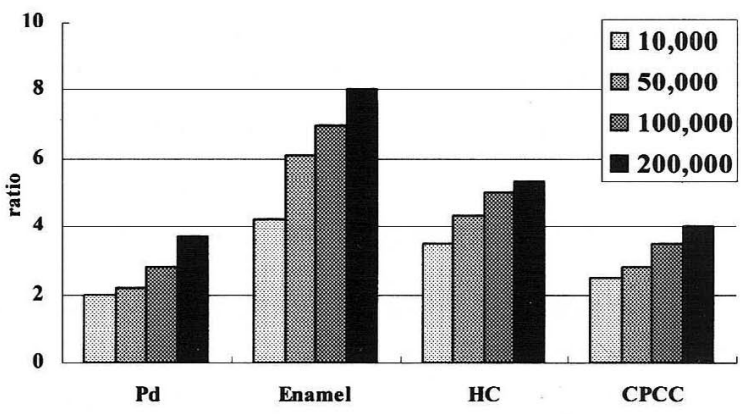

Fig. 10 Changing ratio of worn areas of an alloy ball, enamel, an $\mathrm{HC}$ ball and a castable glass ceramic ball against mechanically polished HC. 


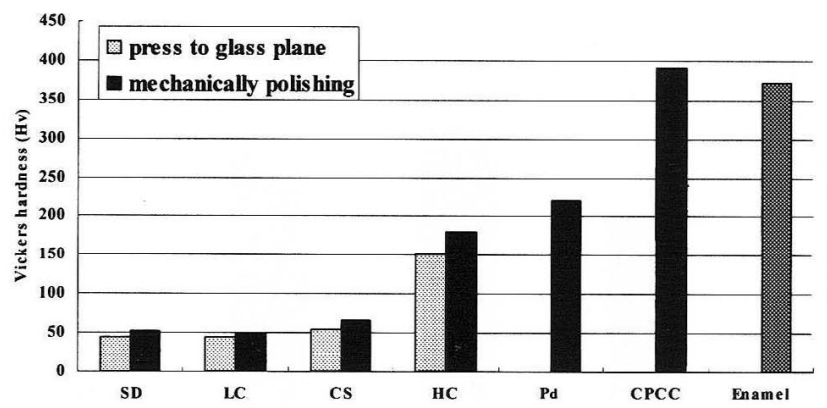

Fig. 11 Vickers hardness values of each material. (Value of enamel refers to reference number 19)

those pressed to a flat glass plane with light-curing only (Fig. 7). Figure 8 shows the SEM of the worn surface of a mechanically polished HC specimen opposed by $12 \% \mathrm{Au}-\mathrm{Ag}-\mathrm{Pd}$ alloy balls. It illustrates a narrow wear track and a little protruding micro-filler compared with as shown in Fig. 4. Figure 9 shows the maximal depth and width of wear of $\mathrm{HC}$ opposed by $12 \% \mathrm{Au}-\mathrm{Ag}-\mathrm{Pd}$ alloy balls, enamel, mechanically polished HC and castable glass ceramic after 200,000 cycles. HC opposed by mechanically polished $\mathrm{HC}$ was the least wear resistant, whereas when opposed by castable glass ceramic, it was the most wear resistant.

Figure 10 shows the changing ratio of the contract areas of the worn alloy ball, enamel, mechanically polishing $\mathrm{HC}$ ball and castable glass ceramic ball for mechanically polished HC planes after $10,000,50,000,100,000$ and 200,000 cycles. The changing ratio of worn enamel was greater in value, in the following the ratio of the worn $\mathrm{HC}$ ball, and the ratio of the worn castable glass ceramic ball were similar to that of the worn alloy ball.

Vickers hardness values for the surfaces of each material are presented in Fig. 11. Hybrid composite resin mechanically polished after heat-curing showed $180 \mathrm{Hv}$, markedly harder than conventional light-curing composite resin materials.

\section{DISCUSSION}

A number of studies were conducted to investigate wear characteristics of composite resin veneering materials in vivo and in vitro ${ }^{5-7)}$. Composite resin materials have demonstrated occlusal wear in the oral environment ${ }^{8)}$ and have had limited usage in occlusal reconstructions. Composite resins have most often been reported excessively worn by enamel and other restorative materials ${ }^{9}{ }^{11}$. The amount of wear depends on such factors as neuromuscular force, lubricants, foreign objects, habits and the restorative materials ${ }^{12)}$. Two methods are commonly used to report the wear of restorative materials, 1) the volume of the material removed (volume loss), and 2) loss of vertical height (height loss). With a sufficient volume loss from the occlusal surface, an opposing tooth or teeth could elongate or change position. The latter is 
more relevant clinically, because it correlates with the diminished vertical dimension of occlusion ${ }^{9}$.

A distinction is made between two-body and three-body abrasive wear. Threebody abrasive wear occurs when a freely moving abrasive medium is placed between two independently moving surfaces, whereas two-body abrasive wear occurs when the abrasive particles are attached to one of the surfaces ${ }^{12)}$. Tranter $e t a l^{13)}$ suggested that the two-body wear device used in their investigation had the ability to rank materials with a three-body wear device $(r=0.94)$, and pooled clinical data with a high degree of correlation $(\mathrm{r}=1.0)^{14)}$.

Wear resistance of composite resin materials is presented as two main clinical components : occlusal-contact wear and contact-free wear. Occlusal-contact wear is a localized process that has been primarily based on theories of microfracture and degradation of a silane coupling agent by hydrolysis and chemical absorption ${ }^{15)}$.

Hybrid composite resin is a new type of composite material, produced by adding a large quantity of ceramic fillers to a resin matrix which is greatly reinforced by a high concentration of ultra-fine ceramic particles.

The present study consisted of 1) wear resistance of $\mathrm{HC}$ material when compared with three composite resin veneering materials, 2) wear resistance of four materials opposed to $\mathrm{HC}$ materials, and 3) the influence of surface characteristics of the $\mathrm{HC}$ specimens.

In the SEM findings, SD and LC with less wear contained low amounts of round ultra-micro fillers. In the worn $\mathrm{HC}$, submicron fillers were raised. The wear and the consistency of the $\mathrm{HC}$ containing high amounts of micro fillers was increased by an ultrafine-particle matrix. SD,LC and CS contained inorganic fillers of $50 \%$ to $60 \%$ and soft organic complex fillers. On the wear sliding test of the $12 \% \mathrm{Au}-\mathrm{Ag}-\mathrm{Pd}$ alloy balls, SD and LC were hard to wear because of the soft fillers and matrix. HC possessed significantly larger depth and width of wear than other materials (Fig. 3), because this was the HC specimen fabricated to press at a flat glass plane and polymerized by light-curing only. There was a monomer rich layer without inorganic fine glass ceramic fillers in the $\mathrm{HC}$ surface layer of the pressed glass side, the thickness of this layer was about $30 \mu \mathrm{m}$. This layer began to wear by the alloy ball first, the amount of wear increased during the sliding wear test. A monomer rich layer was worn, and angular fine glass ceramic fillers protruded. Further, when this surface was smoothed by repeated wearing, it was determined to be maximum (Fig. 12). SEM observations of the worn surface of $\mathrm{HC}$ specimen showed the protruded ultrafine and fine glass ceramic fillers of particle size of $0.02-1.5 \mu \mathrm{m}$ (Fig. 4). The area of the worn alloy ball opposed to $\mathrm{HC}$ as shown in Fig. 7 is smaller and smoother than that opposed to $\mathrm{SD}$, and its boundary is definite as for the worn side of the alloy ball. This was compared in the degree that the hardness of the alloy ball made by $12 \% \mathrm{Au}-\mathrm{Ag}-\mathrm{Pd}$ alloy was similar to that of $\mathrm{HC}$, and it was suggested to be significantly larger than that of SD. The polymerization of a monomer rich layer was promoted by heat-curing. Further, the mechanically polished HC surface was smoothed by pre-cutting fillers, because it was not damaged by protruding 
fillers. The matrix portion of $\mathrm{HC}$ was reinforced by loading ultrafine alumina filler, and remained at the same level as glass particles. HC resulted from the reduction of the differences in the physical properties between fine glass ceramic filler and matrix reinforced by ultrafine filler and reduction in the particle size and increase in the content of the fine glass ceramic filler. The type and content of fillers and the resin matrix influence the localized wear resistance of composite resin ${ }^{5)}$. Decreasing the particle size resulted in a greater incidence of marginal fracture and localized wear. Increasing the particle size tended to result in a more generalized wear pattern ${ }^{6)}$. Hybrid composite resins contain much finer fillers than conventional restorative veneering materials. The smaller the particle diameter, the shorter the distance between the adjacent particles becomes. The matrix in hybrid composite resins has been greatly reinforced by using multi-functional monomers. In addition, a large quantity of ultrafine ceramic filler particles was used. The matrix itself, reinforced by hybridization with ultra-fine particles, takes a further step toward ceramic char-

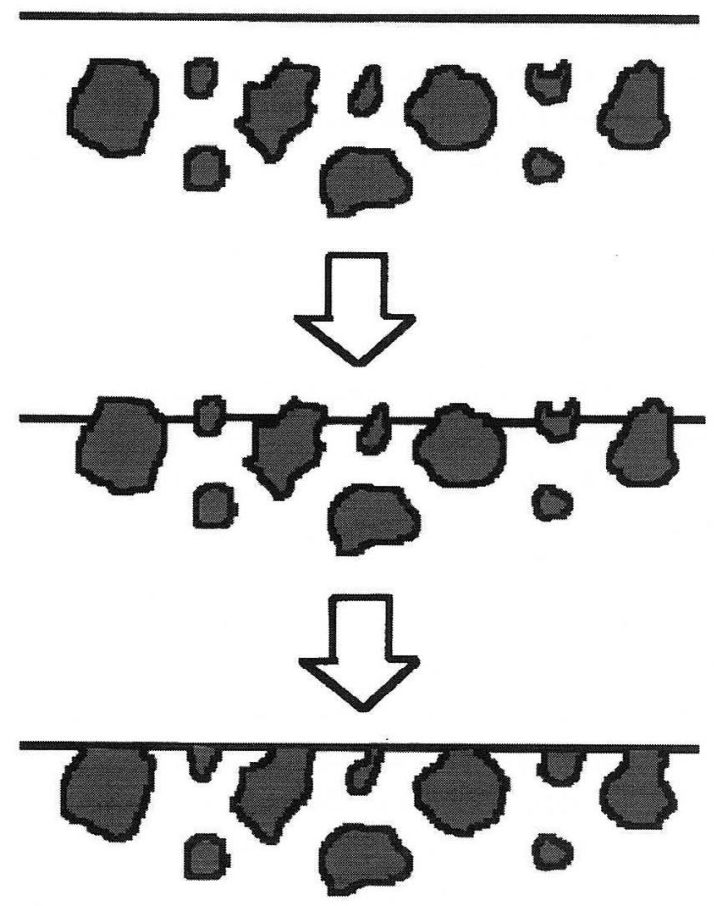

Fig. 12 Changing phase of the HC surface pressed to a glass plane during the sliding wear testing

top: immediately after being polymerized by light-curing.

middle: monomer rich layer was worn, and angular fine glass fillers protruded bottom: smooth surface by repeated sliding wear 
acteristics because the difference in physical properties between the matrix and the filler is significantly reduced. This results in a more uniform material in which the fillers are very evenly dispersed in the matrix. Robert suggested ${ }^{16)}$ that the abraders opposing the hybrid composites showed much heavier wear than those opposing the microfills or amalgam. The heavy wear of the steatite abraders opposing the hybrids was associated with a release of wear particles from the abrader which may have contributed to the higher rate of specimen wear than seen with enamel. On the hybrid composite resin used in this study, the bonding mechanism between the matrix resin and glass ceramic filler was improved by a special surface treatment technique of glass ceramic filler, and fine fillers never release from the matrix resin. Nishino demonstrated ${ }^{17)}$ using the impacting-sliding test that the largest wear was found in the combination of porcelain and hybrid composite resin, he suggested that the resultant sharp surface irregularities as well as the small broken and isolated ceramic filler particles of hybrid composite resin might in turn act as a severe abrasive against the two bodies during the sliding process. Therefore, as for the combination with $\mathrm{HC}$ and a harder material than $\mathrm{HC}$, the fine glass ceramic filler of $\mathrm{HC}$ promotes wear due to surface texture. Furthermore, Nishino suggested ${ }^{17)}$ the second largest amount if wear on the combination of hybrid composite resin and Au-Ag-Pd alloy, showed a deep concave abrasion in the alloy at the impact region in the alloy. He stated that it was surrounded by a slight bank-like periphery, suggesting that it might partly involve plastic deformation by the repeated dropping of hybrid composite resin against ductile alloy. These findings show the characteristic aspects of the impact-sliding test, and the present study found that the isolated fine glass ceramic filler in the matrix influences the wear of each material in a similar manner.

Although the hardness of material is often used as an index of wear resistance, the process of wear is associated with complex mechanisms which influence many factors, and it can not be judged by hardness done. Some studies suggested to a negative correlation between hardness and wear resistance. Hara suggested ${ }^{18)}$ that the relative wear might not always be affected by the hardness but by other physical and mechanical properties such as configuration, surface aspect, elasticity, plasticity and the impact strength of the materials. On the other hand, Craig suggested ${ }^{19)}$ that wear is a function of a number of material and environmental factors, including the nature of wear surfaces; the microscopic contact; interaction between sliding surfaces (i.e., elevated stress; temperature, and flow at contact points, leading to localized yielding, melting, and hardening); lubrication; and different material combinations. In general, wear is a function of both opposing materials and the interface between them. The presence of a lubricating film, such as saliva, separates surfaces during relative motion and reduces frictional forces and wear. It is markedly different for wear resistance in experimental methods. In the present study, the Vickers hardness number of veneering light-curing composite resins (SD, LC and CS) showed $40-60 \mathrm{Hv}$ and about $30 \%$ of $\mathrm{HC}$ hardness, but the wear resistance of these materials opposed to $12 \% \mathrm{Au}-\mathrm{Ag}-\mathrm{Pd}$ alloy were greater larger than that of $\mathrm{HC}$. Although in this experiment the Vickers hardness of $\mathrm{HC}$ was $150 \mathrm{Hv}$, its surface had a 
monomer rich layer and the fine glass ceramic filler was not less than other veneering composite resin materials. The Vickers hardness number of the mechanical polished $\mathrm{HC}$ and $12 \% \mathrm{Au}-\mathrm{Ag}-\mathrm{Pd}$ alloy, and that of enamel and CPCC showed similar values, but a positive correlation between wear resistance and hardness of materials was not always recognized because their surface textures, submicron structures, frictional coefficients, elasticity and so on were different. The newly developed hybrid composite resin is useful as an esthetic posterior restorative material that has advantages of both resinous and inorganic materials. For clinical applications, heatcuring $\left(110^{\circ} \mathrm{C}, 15 \mathrm{~min}\right)$ and mechanical polishing of the hybrid composite resin are essential for all restorations, and hybrid composite resin restorations may work well without excessive wear and help maintain surface gloss.

\section{CONCLUSION}

The wear resistance of a new hybrid composite resin for posterior restoration was investigated in vitro using a two-body sliding wear device. The hybrid composite resin which was compared with other composite resin veneering materials exhibited inferior wear resistance. Scanning electron micrographs made after the wear testing showed protruded micro-fillers of various size on the HC surface pattern. However, after heat-curing, the mechanically polished hybrid composite resin exhibited superior wear resistance. The findings of the present investigation suggested that the wear resistance of the hybrid composite resin was influenced by heat-curing and mechanical polishing of its surface.

\section{REFERENCES}

1) Soderholm, K.J. and Richards, N. D.: Wear resistance of composites : a solved problem?, General Dent 46 : 256-263, 1998.

2) Kern, M., Strub, J.R. and Lu, X.Y.: Wear of composite resin veneering materials in a dual-axis chewing simulator, $J$ Prosthet Dent $26: 372-378,1999$.

3) Knobloch, L. A., Kerby, R. E., Seghi, R. and van Putten, M.: Two-body wear resistance and degree of conversion of laboratory-processed composite materials, Int $J$ Prosthet 12 : 432-438,1999.

4) Mandikos, M. N., McGivney, G. P., Davis, E., Bush, P. J. and Carter, J. M.: A comparison of the wear resistance and hardness of indirect composite resins, $J$ Prothet Dent 85 : 386-395, 2001.

5) Matsumura, H. and Leinfelder, K. F.: Localized three-body wear of six types of composite resin veneering materials, $J$ Prosthet Dent 70 : 207-213, 1993.

6) Leinfelder, K. F., Beaudreau, R. W. and Mazer, R. B.: An in vitro device for predicting clinical wear, Quintessence Int 20 : 755-761,1989.

7) Ekfeldt, A. and Oilo, G.: Occlusal contact wear of prosthodontic materials. An in vivo syudy, Acta Odontol Scand 46 : 159-169, 1988.

8) Sulong, MZAM. and Aziz, R. A.: Wear of materials used in dentistry : a review of the literature. J Prosthet Dent 63 : 342-349, 1990.

9) Embong, A., Glyn, J. and Harrison, A.: The wear effects of selected composites on restorative materials and enamel. Dent Mater $3: 236-240,1987$.

10) Sakaguchi, R. L., Douglas, W. H., DeLong, R. and Pintado, M. R.: The wear of a 
posterior composite in an artificial mouth : a clinical correlation. Dent Mater 2 : 235-240, 1986.

11) DeLong, R., Pintado, M.R. and Douglas, W. H.: The wear of enamel opposing shaded ceramic restorative materials: An in vitro study. J Prosthet Dent 68:42-48, 1992.

12) Jerome, A. M., Florian, J. K. and Elmer, J. W.: Occlusal wear in prosthodontics. J Ame Dent A 82 : 154-159, 1971.

13) Soderholm, K. J. and Richards, N. D.: Wear resistance of composites: A solved problem? Gen Dent 46 : 256-263, 1998.

14) Tranter, T., Seghi, L. A. and Seghi, R. R.: Rank correlation between in-vivo and three in-vitro methods of clinical wear evaluation. J Dent Res 76 : 201, 1994.

15) Taylor, D. F., Bayne, S. C., Leinfelder, K. F., Davis, S. and Koch, G. G.: Pooling of long term clinical wear data for posterior composites. Am J Dent 7:167-174, 1994.

16) Robert, W. W., John, F. M. and Angus, W. G.: Wear characteristics in a two-body wear test, Dent Mater $10: 269-274,1994$.

17) Nishino, T., Asano, T., Nagamatsu, H. and Kojo, T.: Wearing behavior of a hybrid composite resin for crown and Bridge, Dent Mater $J$ 20 : 216-226, 2001.

18) Hara, K.: Experimental study on wear of crown and bridge materials and tooth enamel by impacting-sliding test, $J$ Kyushu Dent Soc 44:615-631, 1990. (in Japanese)

19) Craig, R. G.: Restorative dental materials, 10th ed., Mosby, St.Louis, 1997, 86-92. 